\title{
Editorial Letter to the Special Issue on Newborn Screening in Latin America (Commemorating the Silver Jubilee of the Latin American Society for Inborn Errors of Metabolism and Neonatal Screening - SLEIMPN)
}

Journal of Inborn Errors of Metabolism \& Screening 2021, Volume 9: e20210023 DOI: https://doi.org/10.1590/2326-4594JIEMS-2021-0023

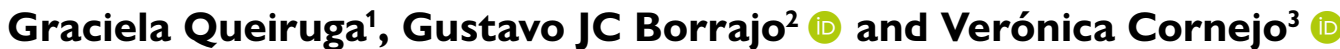

Newborn screening (NBS) in Latin America made its first steps in the mid-seventies, starting out on two almost simultaneously launched initiatives that opened the way towards the implementation of a system of prevention of potentially catastrophic diseases. The first one arose in Mexico in 1973, when Dr. Antonio Velázquez, after undergoing training with Dr. Robert Guthrie, started a project for the detection of phenylketonuria (PKU) and other amino acid disorders. The second initiative came up in São Paulo - Brazil, when Dr. Benjamin Schmidt and colleagues started the project "A National plan for study and detection of inborn errors of metabolism (IEM) that could lead to mental deficiency", and in 1976 created a Laboratory for the detection of PKU and IEM causing mental deficiency, thus becoming the first NBS program implemented in Latin America [1].

Nevertheless, NBS in the region began to be implemented in a moderately organized way in the mid-eighties, but only in some countries, Cuba being the first one to launch a national NBS program in 1986. Between 1985 and 1990 several countries as Argentina, Brazil, Chile, Colombia, Costa Rica, Mexico, Uruguay and Venezuela started pilot programs or NBS tests conducted at request. However, only few ones achieved the implementation of national programs in the short term, such as the case of Costa Rica in 1990, Chile in 1992 and Uruguay in 1994 [1].

In 1994, an informal meeting of professionals and scientists dedicated to IEM and NBS from different Latin American countries was carried out in Mexico and the formation of the Latin American Metabolic Information Network (LAMIN) was decided. A second meeting, held in Chile in 1995, was a further step on the establishment of this network [2].
In August 1996, and giving continuity to the previous initiatives, Dr. Roberto Giugliani and colleagues organized the 1996 LAMIN Meeting in Porto Alegre - Brazil, as a pre-congress satellite activity of the IX Congress of Human Genetics that would take place in Rio de Janeiro few days later. The scientific program was planned to address five mayor topics: selective screening, neonatal screening, information registries, computer network and quality control. The meeting had almost two hundred attendees, with most of the groups represented exposing their regional experiences, thus delineating a preliminary panorama of the IEM and NBS situation in Latin America by those years. Undoubtedly, and not disregarding the importance of the scientific program of such a meeting, the most important 1996 LAMIN Meeting contribution was having placed the milestone for the creation of the Latin American Society for Inborn Errors of Metabolism and Neonatal Screening (SLEIMPN), and planning a new meeting to be held the following year in La Havana - Cuba.

\footnotetext{
${ }^{1}$ Universidad de la República, Consejo de la Facultad de Química, Montevideo, Uruguay.

${ }^{2}$ Fundación Bioquímica Argentina, Detección de Errores Congénitos, La Plata, Argentina.

${ }^{3}$ Universidad de Chile, Instituto de Nutrición y Tecnología de los Alimentos, Laboratorio de Genética y Enfermedades Metabólicas, Santiago, Chile.
}

Received May 07, 2021. Accepted for publication June 14, 2021.

Corresponding Author:

Gustavo JC Borrajo.

Email: borrajog@net-alliance.net 
In that way, the "First Latin American Meeting of NBS and IEM" was held in September 1997 chaired by Dr. José Luis Fernández Yero within the framework of the celebration of the "Tenth Anniversary of the Cuban NBS Program for Congenital Hypothyroidism". In that meeting the statutes of this emerging society were discussed and approved, the SLEIMPN was officially created, and Prof. Verónica Cornejo was elected as president for the next period.

SLEIMPN has the particularity of being a mixed scientific society that aggregates health professionals working in IEM as well as in NBS. It provides support to its members for trainees and external experts visiting through an established scholarship program since 2007 and organizes its congress every two years. Undoubtedly, all these activities have contributed to form a critical mass in both working areas, thereby achieving the implementation of new NBS programs in further countries of the region and, at the same time, consolidating clinical centers with professionals with experience in the diagnosis, therapy and follow-up of IEM [3].

Until today, SLEIMPN has organized 10 Latin American Meetings, one joint Latin American and International NBS
Meeting, and one International Congress of IEM, with the participation of outstanding speakers from Latin America and other continents in an academic and professional environment of cordiality. Due to the SARS-CoV-2 pandemic, the next congress will be held in May 2022 in the Dominican Republic, chaired by Dr. Ceila Pérez (Table 1).

This year, the silver jubilee of this thriving society is being celebrated and we had the honor to have been invited as editors of this special issue of JIEMS dedicated to NBS in Latin America.

Many people have contributed to the strengthening of the SLEIMPN along the years, allowing its continuous growth, and major advances were achieved. Some of these groups and accomplishments are described in the manuscripts of this collection, listed at the end of this editorial.

Through this special supplement we would like to thank and acknowledge to all those that in any way have shared their knowledge and dedicated part of their professional and personal time to contribute to the great endeavor of building the Latin American Society for Inborn Errors of Metabolism and Neonatal Screening - SLEIMPN.

Table 1. Summary of Inborn Errors of Metabolism and Newborn Screening Latin American Meetings hold from 1997 to 2019 organized by the SLEIMPN.

\begin{tabular}{|c|c|c|c|}
\hline Year & City - Country & Congress & SLEIMPN President \\
\hline 1997 & La Havana - Cuba & I SLEIMPN Meeting & Dr. José Luis Fernández Yero \\
\hline 1999 & Santiago - Chile & II SLEIMPN Meeting & Prof. Verónica Cornejo \\
\hline 2001 & Cartagena - Colombia & III SLEIMPN Meeting & Dr. Luis Alejandro Barrera \\
\hline 2003 & Iguazú - Argentina & IV SLEIMPN Meeting & Dr. Néstor Chamoles \\
\hline 2005 & San José - Costa Rica & V SLEIMPN Meeting & Dr. Manuel Saborio \\
\hline 2007 & Punta del Este - Uruguay & VI SLEIMPN Meeting & Dr. Graciela Queiruga \\
\hline 2009 & Cancún - Mexico & VII SLEIMPN and $7^{\text {th }}$ ISNS ${ }^{\dagger}$ Meeting & Dr. Marcela Vela \\
\hline 2011 & Cusco - Peru & VIII SLEIMPN Meeting & Dr. Cecilia Bonilla \\
\hline 2013 & Medellín - Colombia & IX SLEIMPN Meeting & Dr. Luis Alejandro Barrera \\
\hline 2015 & Santiago - Chile & X SLEIMPN Meeting & Dr. Juan Francisco Cabello \\
\hline 2017 & Rio de Janeiro - Brazil & $13^{\text {th }}$ ICIEM $¥$ Meeting & Dr. Roberto Giugliani \\
\hline 2019 & Buenos Aires - Argentina & XI SLEIMPN Meeting & Dr. José Abdenur \\
\hline
\end{tabular}

†ISNS: International Society for Neonatal Screening.

₹ ICIEM: International Congress of Inborn Errors of Metabolism.

\section{Manuscripts included in this special issue}

1. Importance of Studying Older Siblings of Patients Identified by Newborn Screening: A Single-center Experience in Mexico. https://doi.org/10.1590/2326-4594-JIEMS-2021-0001

Ibarra-González, Isabel; Fernández-Lainez, Cynthia; GuillénLópez, Sara; López-Mejía, Lizbeth; Belmont-Martínez, Leticia; Carrillo-Nieto, Itzel; Vela-Amieva, Marcela
2. Twenty Years of Neonatal Screening for Sickle Cell Disease in Brazil: The Challenges of a Continental Country with High Genetic Heterogeneity. https://doi.org/10.1590/23264594-JIEMS-2021-0002

Pimentel, Helena; Domingos, Claudia; Castro, Simone

3. Quantitative Determination of Branched-chain Amino Acids in Dried Blood Spot Samples by Liquid Chromatography-Mass Spectrometry and its Application 
in Diagnosis and Follow-up of Chilean Patients with Maple Syrup Urine Disease. https://doi.org/10.1590/23264594-JIEMS-2021-0005

Fuenzalida, Karen; Valiente, Alf; Faundez, Andres; Guerrero, Patricio; Soto, Vivian; Leal-Witt, María Jesús; Cabello, Juan F; Cornejo, Verónica

4. Consolidation of the Neonatal Screening Program as a Public Health Program in Paraguay. https://doi. org/10.1590/2326-4594-JIEMS-2021-0006

Ascurra, Marta; Alvarez, Pamela; Ortiz-Paranza, Lourdes; Blanco, Fabiola; Valenzuela, Adriana; Insaurralde, Anahi; Salinas, Mirna; Rodriguez, Stella; Porzio, Giovanna; Nuñez, Andrea

5. 25 Years of the Newborn Screening in Uruguay. https:// doi.org/10.1590/2326-4594-JIEMS-2021-0008

Queijo, Cecilia; Lemes, Aida; Queiruga, Graciela

6. How Long are Residual Newborn Screening Specimens Useful for Retesting When Stored in Suboptimal and Uncontrolled Conditions of Temperature and Humidity? https://doi.org/10.1590/2326-4594-JIEMS-2021-0010

Borrajo, Gustavo; Doña, Vanina

7. Amino Acids and Acylcarnitines Reference Values for Neonatal Screening of Inborn Errors of Metabolism in
Colombia by tandem mass spectrometry. https://doi. org/10.1590/2326-4594-JIEMS-2021-0012

Bermudez, Antonio; Robayo, Dora; Porras, Gloria; Acosta, María Amparo

8. Spatial Distribution of Congenital Disorders Diagnosed by the Newborn Screening Program in Ecuador. https:// doi.org/10.1590/2326-4594-JIEMS-2020-0016

Pozo-Palacios, Juan; García-Díaz, Génesis; Cruz, Fernando; Porras, Fabián; Heras, Jessica; Cano-Pérez, Eder

\section{Declaration of Conflicting Interests}

The authors declare that there are no financial, personal, institutional or academic conflicts of interests that could have interfered in the preparation of this special supplement.

\section{References}

1. Borrajo GJC. Newborn screening in Latin America at the beginning of the 21 st century. J Inherit Metab Dis. 2007;30(4):466-81. doi: 10.1007/s10545-007-0669-9

2. Giugliani R. Foreword to the proceedings of the 1996 LAMIN meeting; 1996.

3. Borrajo GJC. Newborn screening in Latin America: a brief overview of the state of the art. Am J Med Genet. 2021;1-7. https://doi.org/10.1002/ajmg.c.31899 